\title{
The effect of ischemic time on survival after heart transplantation varies by donor age: An analysis of the United Network for Organ Sharing database
}

Mark J. Russo, MD, MS, ${ }^{a, b}$ Jonathan M. Chen, MD, ${ }^{a}$ Robert A. Sorabella, BA, ${ }^{a}$ Timothy P. Martens, MD, ${ }^{a}$ Mauricio Garrido, MD, ${ }^{a}$ Ryan R. Davies, MD, ${ }^{a}$ Isaac George, MD, ${ }^{\text {a }}$ Faisal H. Cheema, MD, ${ }^{a}$ Ralph S. Mosca, MD, ${ }^{a}$ Seema Mital, MD, ${ }^{c}$ Deborah D. Ascheim, MD, ${ }^{\text {b,d }}$ Michael Argenziano, MD, ${ }^{a}$ Allan S. Stewart, MD, ${ }^{a}$ Mehmet C. Oz, MD, and Yoshifumi Naka, MD, PhDa

From the Division of Cardiothoracic Surgery, Department of Surgery, College of Physicians and Surgeons ${ }^{\mathrm{a}}$; International Center for Health Outcomes and Innovation Research $^{\text {b }}$, Division of Cardiology, Department of Pediatrics, College of Physicians and Surgeons; ${ }^{\mathrm{C}}$ Division of Cardiology, Department of Medicine, College of Physicians and Surgeons, ${ }^{\mathrm{d}}$ Columbia University, New York.

This work was supported in part by Health Resources and Services Administration contract 231-00-0115. The content is the responsibility of the authors alone and does not necessarily reflect the views or policies of the Department of Health and Human Services, nor does mention of trade names, commercial products, or organizations imply endorsement by the U.S. Government.

Received for publication Feb 22, 2006; revisions received July 3, 2006; accepted for publication Sept 7, 2006.

Reprint requests: Yoshifumi Naka, MD, $\mathrm{PhD}$, Division of Cardiothoracic Surgery, New York-Presbyterian Hospital/Columbia, Milstein Hospital Bldg Room 7-435, 177 Fort Washington Avenue, New York, NY 10032 (E-mail: yn33@columbia.edu).

J Thorac Cardiovasc Surg 2007;133:554-9

$0022-5223 / \$ 32.00$

Copyright $\odot 2007$ by The American Association for Thoracic Surgery

doi:10.1016/j.jtcvs.2006.09.019
Objectives: (1) To examine the interaction of donor age with ischemic time and their effect on survival and (2) to define ranges of ischemic time associated with differences in survival.

Methods: The United Network for Organ Sharing provided de-identified patientlevel data. The study population included 33,640 recipients undergoing heart transplantation between October 1, 1987, and December 31, 2004. Recipients were divided by donor age into terciles: 0 to 19 years $(\mathrm{n}=10,814 ; 32.1 \%), 20$ to 33 years $(11,410,33.9 \%)$, and 34 years or more $(11,416,33.9 \%)$. Kaplan-Meier survival functions and Cox regression were used for time-to-event analysis. Receiver operating characteristic curves and stratum-specific likelihood ratios were generated to compare 5-year survival at various thresholds for ischemic time.

Results: In univariate Cox proportional hazards regression, the effect of ischemic time on survival varied by donor age tercile: 0 to 19 years $(P=.141), 20$ to 33 years $(P<.001)$, and 34 years or more $(P<.001)$. These relationships persisted in multivariable regression. Threshold analysis generated a single stratum (0.37-12.00 hours) in the 0 - to 19 -year-old group with a median survival of 11.4 years. However, in the 20- to 33-year-old-group, 3 strata were generated: 0.00 to 3.49 hours (limited), 3.50 to 6.24 hours (prolonged), and 6.25 hours or more (extended), with median survivals of 10.6, 9.9, and 7.3 years, respectively. Likewise, 3 strata were generated in the group aged 34 years or more: 0.00 to 3.49 (limited), 3.50 to 5.49 (prolonged), and 5.50 or more (extended), with median survivals of 9.1, 8.5, and 6.3 years, respectively.

Conclusions: The effect of ischemic time on survival after heart transplantation is dependent on donor age, with greater tolerance for prolonged ischemic times among grafts from younger donors. Both donor age and anticipated ischemic time must be considered when assessing a potential donor.

$\mathrm{D}$ uring the past 30 years of heart transplantation, it has become common practice to procure hearts from younger donors even when extended ischemic times are required. However, among older donors, convention dictates that ischemic time should be limited to 4 hours or less.

To test these practices, this study examined the effect of ischemic time on recipient survival within various donor age ranges. In addition, it sought to define thresholds for ischemic time associated with worse survival within these donor age groups. To achieve sufficient power to detect differences in survival across a broad range of ischemic times, we analyzed the United Network for Organ Sharing (UNOS) registry, which includes all heart transplants from US centers since 1987. 


\section{Abbreviations and Acronyms \\ $\mathrm{CI}=$ confidence interval \\ ROC = receiver operating characteristic \\ SSLR = stratum-specific likelihood ratio \\ UNOS = United Network for Organ Sharing}

\section{Materials and Methods}

\section{Data Collection and Study Population}

UNOS provided de-identified patient-level data from the Thoracic Registry (data source No. 092005-7). The registry includes all heart transplant recipients and donors in the United States since October 1, 1987. This study included 34,556 heart transplants performed from October 1, 1987, to December 31, 2004. Patients with a previous heart transplant were excluded from the study population ( $\mathrm{n}=916,2.5 \%)$. Recipients were divided by donor age into terciles: 0 to 19 years $(\mathrm{n}=10,814 ; 32.2 \%), 20$ to 33 years $(11,410,33.9 \%)$, and 34 years or more $(11,416,33.9 \%)$.

\section{Data Analysis}

All data were analyzed with a standard statistical software package, Stata 9 (Stata Corp, College Station, Tex). Continuous variables were reported as means \pm standard deviation and compared using the Student's $t$ test. The chi-square test was used to compare categoric variables. All reported $P$ values were 2 -sided.

The primary outcome measure was survival reported as median survival and incidence rate of death per 100 patient-years with 95\% confidence intervals (CIs). Kaplan-Meier analysis with Cox proportional hazards regression was used for time-to-event analysis. Outcome of interest was death $(\mathrm{n}=13,478,40.1 \%)$ or retransplant $(\mathrm{n}=840,2.5 \%)$, whichever came first. Patients lost to follow-up $(\mathrm{n}=2,168,6.44 \%)$ or alive on September 15, 2005 $(17,154,51.0 \%)$ were censored at the date of last known followup. A multivariate Cox regression was performed (backward, remove $P>.10$ ) in which the dependent variable was survival and the independent variables were donor age, recipient age, ischemic cause of disease, intensive care unit immediately before transplant, UNOS status $1 / 1 \mathrm{~A} / 1 \mathrm{~B}$ at transplant, waiting time, year of transplant, and ischemic time. To assess the impact of ischemic time on early and late mortality, the incidence rate of death per 100 patient-years was calculated at multiple time intervals $(<30$ days, 30 days to 1 year, $1-5$ years, $5-10$ years, and $\geq 10$ years). Receiver operating characteristic (ROC) curves and stratum-specific likelihood ratios (SSLRs) were used in threshold analysis. ROC curves were generated by plotting sensitivity on the ordinate and 1-specificity on the abscissa with ischemic time as a continuous variable and mortality (at 5 years) as a binary outcome. ${ }^{1,2}$ SSLRs and $95 \%$ CIs were generated using data cut-points at regular intervals as previously described. ${ }^{3,4}$ Cut-points, or threshold values, for ischemic time were determined by combining adjacent ischemic time strata in 15 -minute ( 0.25 hours) intervals with other statistically indistinct strata based on the presence of SSLRs with overlapping 95\% CIs. Cut-points occurred when 2 statistically distinct strata could be formed. This process was repeated until no additional cut-points were found.

\section{Results}

\section{Study Population}

Analysis included 178,031.1 at-risk years with a median survival of 10.3 years. The mean ischemic time for the 0 - to 19-year-old, 20- to 33-year-old, and $\geq 34$-year-old donor terciles was $3.1 \pm 1.2$ hours, $2.8 \pm 1.0$ hours, and $2.9 \pm 1.0$ hours, respectively. Table 1 summarizes recipient and donor characteristics by donor age terciles and ischemic time strata.

\section{Survival Analysis}

In univariate Cox proportional hazards regression, the effect of ischemic time on survival varied by donor age terciles: 0 to 19 years $(P=.141), 20$ to 33 years $(P<.001)$, and 34 years or more $(P<.001)$. In multivariate analysis, increasing donor age $(P=.006)$, increasing recipient age $(P<$ $.001)$, and earlier year of transplant $(P<.001)$ were associated with worse survival in the $\leq 19$-year-old donor age tercile; increasing donor age $(P<.001)$, increasing recipient age $(P<.001)$, ischemic cause $(P<.001)$, intensive care unit pretransplant $(P=.004)$, earlier year of transplant $(P<.001)$, and increasing ischemic time $(P<.001)$ were associated with worse survival in the 20- to 33-year-old donor age tercile; and increasing donor age $(P<.001)$, increasing recipient age $(P=.014)$, ischemic cause $(\mathrm{P}<$ $.001)$, intensive care unit pretransplant $(P=.004)$, earlier year of transplant $(P<.001)$, and increasing ischemic time $(P<.001)$ were associated with worse survival in the $\geq 34$-year-old donor age tercile. Table 2 demonstrates a trend toward an increase in the incidence rate of death at nearly every time point.

\section{Receiver Operating Characteristic}

ROC curves and the corresponding area under the curve were 0.53 (0.52-0.55), $0.52(0.51-0.53)$, and 0.53 (0.520.55 ) for the 0 - to 19-year-old, 20- to 33-year-old, and $\geq 34$-year-old donor groups, respectively. The results of threshold analysis are presented in Table 2. SSLR analysis generated only a single stratum (0.37-12.00 hours) in the 0 - to 19-year-old group with a median survival of 11.4 years; however, in the 20- to 33-year-old group, 3 strata were generated: 0.00 to 3.49 hours (limited) with an SSLR of 0.97 (0.94-0.99) and median survival of 10.6 years; 3.50 to 6.24 hours (prolonged) with an SSLR of 1.11 (1.01-1.23) and median survival of 9.9 years; and 6.25 hours or more (extended) with an SSLR of 2.87 (1.29-6.40) and median survival of 7.3 years. Likewise, 3 strata for ischemic time were generated in the $\geq 34$-yearold group: 0.00 to 3.49 hours (limited) with an SSLR of 0.94 (0.92-0.97) and median survival of 9.1 years; 3.50 to 5.49 hours (prolonged) with an SSLR of 1.15 (1.06-1.27) and median survival of 8.5 years; and 5.50 hours or more 
TABLE 1. Recipient-donor characteristics by donor age terciles and ischemic time strata

\begin{tabular}{|c|c|c|c|c|c|c|}
\hline \multirow[b]{2}{*}{ Donor age tercile } & \multirow[b]{2}{*}{ Years old } & \multirow[b]{2}{*}{$\leq 19$} & \multicolumn{4}{|c|}{$20-33$} \\
\hline & & & Limited & Prolonged & Extended & Subtotal \\
\hline Ischemic time & $\mathrm{h}$ & & $0.00-3.49$ & $3.50-6.24$ & $\geq 6.25$ & \\
\hline $\mathrm{n}$ & $\mathrm{n}$ & 10,814 & 10,817 & 547 & 46 & 11,410 \\
\hline Mean donor age & y & $12.9 \pm 6.3$ & $25.6 \pm 4.1$ & $25.7 \pm 4.1$ & $25.5 \pm 4.1$ & $25.6 \pm 4.1$ \\
\hline Mean recipient age & y & $36.3 \pm 23.4$ & $49.7 \pm 12.5$ & $48.7 \pm 14.9$ & $48.1 \pm 15.6$ & $49.8 \pm 12.6$ \\
\hline \multirow[t]{2}{*}{ Ischemic cause of heart failure } & $\mathrm{n} \%$ & 3553 & 5247 & 277 & 22 & 5546 \\
\hline & & $32.9 \%$ & $48.5 \%$ & $50.6 \%$ & $47.8 \%$ & $48.6 \%$ \\
\hline Waiting time & $\mathrm{d} S \mathrm{SD}$ & $120.1 \pm 200.5$ & $151.5 \pm 237.4$ & $164 \pm 252.3$ & $270.1 \pm 372.7$ & $152.6 \pm 239.0$ \\
\hline \multirow[t]{2}{*}{ UNOS status 1 at transplant } & $\mathrm{n} \%$ & 6477 & 6281 & 393 & 30 & 6704 \\
\hline & & $59.9 \%$ & $58.1 \%$ & $71.8 \%$ & $65.2 \%$ & $58.8 \%$ \\
\hline \multirow[t]{2}{*}{ ICU at time of transplant } & $\mathrm{n} \%$ & 5616 & 4943 & 259 & 9 & 5211 \\
\hline & & $51.9 \%$ & $45.7 \%$ & $47.3 \%$ & $19.6 \%$ & $45.7 \%$ \\
\hline
\end{tabular}

UNOS, United Network for Organ Sharing; ICU, intensive care unit; $S D$, standard deviation; $C l$, confidence interval.

(extended) with an SSLR of 2.4 (1.48-3.97) and median survival of 6.3 years.

\section{Discussion}

Previous studies exploring the relationship between ischemic time and survival have reported conflicting findings. A number of studies examining determinants of long-term survival demonstrated an inverse relationship between ischemic time and posttransplant survival, ${ }^{5,6}$ whereas other studies found no association between ischemic time and survival. ${ }^{7-9}$ These conflicting findings may result from limitations in sample size or range of ischemic times. It is also possible that other donor characteristics influencing tolerance for cold ischemia were not considered. By examining the national experience with heart transplantation over the past 2 decades and considering the effect of donor age on tolerance for cold ischemia, this study overcomes the limitations of previous studies.

The findings in this study demonstrate that the impact of ischemic time on survival differs by donor age. Among donors aged 19 years or less, there was no statistically significant relationship between ischemic time and survival. Furthermore, in threshold analysis, no threshold could be found in which a significant difference in survival existed. It is possible that the heterogeneity of recipients in the $\leq 19$-year-old donor age tercile confounded the relationship between ischemic time and survival in this tercile, but further analysis not presented

TABLE 2. Outcomes by donor age terciles and ischemic time strata

\begin{tabular}{|c|c|c|c|c|c|c|}
\hline \multirow[b]{2}{*}{ Donor age tercile } & \multirow[b]{2}{*}{ Years old } & \multirow[b]{2}{*}{$\leq 19$} & \multicolumn{4}{|c|}{$20-33$} \\
\hline & & & Limited & Prolonged & Extended & Subtotal \\
\hline Ischemic time & $\mathrm{h}$ & & $0.00-3.49$ & $3.50-6.24$ & $\geq 6.25$ & \\
\hline & $95 \% \mathrm{Cl}$ & & $(0.94-0.99)$ & $(1.01-1.23)$ & $(1.29-6.40)$ & \\
\hline $\begin{array}{l}\text { Median survival } \\
\text { Incidence rate of death }\end{array}$ & $\mathrm{y}$ & 11.4 & 10.6 & 9.9 & 7.3 & 10.5 \\
\hline $0-30 \mathrm{~d}$ & $\begin{array}{l}/ 100 \text { person }^{*} y \\
95 \% \mathrm{Cl}\end{array}$ & $\begin{array}{c}76.9 \\
(71.2-83.0)\end{array}$ & $\begin{array}{c}54.7 \\
(49.5-60.5)\end{array}$ & $\begin{array}{c}83.5 \\
(71.8-97.0)\end{array}$ & $\begin{array}{c}225.6 \\
(107.5-473.2)\end{array}$ & $\begin{array}{c}61.8 \\
(56.9-67.2)\end{array}$ \\
\hline $30 \mathrm{~d}$ to $1 \mathrm{y}$ & $\begin{array}{c}/ 100 \text { person }^{*} y \\
95 \% \mathrm{Cl}\end{array}$ & $\begin{array}{c}9.5 \\
(8.9-10.2)\end{array}$ & $\begin{array}{c}9.4 \\
(8.7-10.2)\end{array}$ & $\begin{array}{c}8.9 \\
(7.7-10.3)\end{array}$ & $\begin{array}{c}6.8 \\
(1.7-27.3)\end{array}$ & $\begin{array}{c}9.3 \\
(8.7-10.0)\end{array}$ \\
\hline $1-5 y$ & $\begin{array}{c}/ 100 \text { person }^{*} \mathrm{y} \\
95 \% \mathrm{Cl}\end{array}$ & $\begin{array}{c}4.0 \\
(3.8-4.2)\end{array}$ & $\begin{array}{c}4.4 \\
(4.1-4.6)\end{array}$ & $\begin{array}{c}4.7 \\
(4.2-5.3)\end{array}$ & $\begin{array}{c}10.9 \\
(5.4-21.8)\end{array}$ & $\begin{array}{c}4.5 \\
(4.2-4.7)\end{array}$ \\
\hline
\end{tabular}

$\mathrm{Cl}$, Confidence interval. 
TABLE 1. Continued

\begin{tabular}{|c|c|c|c|c|}
\hline \multicolumn{4}{|c|}{$\geq 34$} & \multirow[b]{2}{*}{ Total } \\
\hline Limited & Prolonged & Extended & Subtotal & \\
\hline $0.00-3.49$ & $3.50-5.49$ & $\geq 5.50$ & & \\
\hline 9224 & 2051 & 141 & 11,416 & 33,640 \\
\hline $43.7 \pm 7.0$ & $44.6 \pm 4.1$ & $43.5 \pm 7.4$ & $43.7 \pm 7.0$ & $43.7 \pm 7.0$ \\
\hline $52 \pm 11.4$ & $51.5 \pm 13.3$ & $52.7 \pm 13.5$ & $52 \pm 11.6$ & $46.2 \pm 18.0$ \\
\hline 4625 & 1085 & 78 & 5788 & 14,887 \\
\hline $50.1 \%$ & $52.9 \%$ & $55.3 \%$ & $50.7 \%$ & $44.3 \%$ \\
\hline $162.7 \pm 241.9$ & $187.5 \pm 274.8$ & $166.5 \pm 243.8$ & $163.6 \pm 243.2$ & $145.8 \pm 229.7$ \\
\hline 5573 & 1453 & 98 & 7124 & 20,305 \\
\hline $60.4 \%$ & $70.8 \%$ & $69.5 \%$ & $62.4 \%$ & $60.4 \%$ \\
\hline 4230 & 1053 & 67 & 5350 & 16,177 \\
\hline $45.9 \%$ & $51.3 \%$ & $47.5 \%$ & $46.9 \%$ & $48.1 \%$ \\
\hline
\end{tabular}

here suggests that this was unlikely. Multivariable Cox proportional hazards regression analysis, as described above, limited to narrower recipient age ranges ( $<1$ year, 1-6 years, 6-11 years, $12-18$ years, and $\geq 18$ years) was also unable to demonstrate a statistical relationship between ischemic time and survival in any recipient age range.

Conversely, among the 2 older donor age terciles (20-33 years and $\geq 34$ years), a statistically significant relationship was observed between ischemic time and survival. In threshold analysis, survival was diminished in both the 20- to 33-year-old and $\geq 34$-year-old terciles with prolonged ischemic times (3.50-6.24 hours and 3.50-5.49 hours, respectively), and posttransplant sur- vival was further diminished with extended ischemic times ( $\geq 6.25$ hours and $\geq 5.50$ hours, respectively). It should be noted that when comparing limited with prolonged ischemic times in both of these older donor age terciles, survival was diminished by less than 250 days. Therefore, although a statistically significant difference in survival existed, the difference was of little clinical consequence. However, when comparing limited with extended ischemic times within both of these older age groups, the median survival decreased by more than 1000 days. Furthermore, when moving within each of the 2 older donor age terciles from the limited to prolonged to extended strata, there is a trend at nearly every time point toward an increase in the incidence rate of death

TABLE 2. Continued

\begin{tabular}{|c|c|c|c|c|}
\hline \multicolumn{4}{|c|}{$\geq 34$} & \multirow[b]{2}{*}{ Total } \\
\hline Limited & Prolonged & Extended & Subtotal & \\
\hline $0.00-3.49$ & $3.50-5.49$ & $\geq 5.50$ & & \\
\hline 0.94 & 1.15 & 2.42 & & \\
\hline$(1.06-1.27)$ & $(1.48-3.97)$ & & & \\
\hline 9.1 & 8.5 & 6.3 & 8.9 & 10.3 \\
\hline 8.4 & 9.7 & 15.0 & 8.7 & 7.4 \\
\hline (8.1-8.7) & (9.1-10.2) & $(11.7-19.2)$ & $(8.5-9.0)$ & (7.3-7.5) \\
\hline 84.1 & 119.7 & 237.8 & 94.6 & 77.7 \\
\hline$(77.3-91.4)$ & $(106.0-135.2)$ & $(158.0-357.8)$ & (88.4-101.3) & $(74.4-81.2)$ \\
\hline 11.2 & 12.7 & 21.5 & 11.7 & 10.2 \\
\hline$(10.4-12.1)$ & $(11.3-14.3)$ & $(13.6-34.1)$ & $(11.0-12.4)$ & (9.8-10.5) \\
\hline 5.3 & 5.6 & 6.8 & 5.4 & 4.6 \\
\hline$(5.0-5.7)$ & $(5.0-6.2)$ & (4.1-11.2) & $(5.1-5.7)$ & $(4.5-4.8)$ \\
\hline 7.5 & 7.2 & 3.6 & 7.4 & 6.4 \\
\hline$(7.0-8.0)$ & $(6.3-8.3)$ & $(1.2-11.1)$ & $(7.0-7.9)$ & $(6.2-6.6)$ \\
\hline 10.4 & 11.2 & 18.0 & 10.6 & 9.3 \\
\hline$(9.3-11.7)$ & $(8.8-14.4)$ & (6.8-48.1) & $(9.6-11.8)$ & $(8.8-9.8)$ \\
\hline
\end{tabular}

$\mathrm{Cl}$, Confidence interval. 
(Table 2). Therefore, it seems that in these donor age ranges, the negative impact of longer ischemic times on survival persists over time.

\section{Limitations}

Recipient-donor characteristics were not uniform across groups. However, potential differences in pretransplant recipient morbidity or donor quality were unlikely to confound comparisons of ischemic time strata within the same donor age terciles and, therefore, the findings in this study. As summarized in Table 1, there is little evidence that, within the same donor age terciles, recipients of grafts subjected to longer ischemic times were sicker. In fact, when the prolonged and extended strata within each of the 2 older donor age terciles were compared, the extended strata had a lower percentage of patients admitted to the intensive care unit pretransplant and relatively fewer patients with UNOS status 1/1A/1B. Moreover, even when using multivariable Cox proportional hazards regression to control for other patients' characteristics, the observed relationship between ischemic time and survival persisted. Conversely, because donor and recipient characteristics known to influence posttransplant survival, including recipient age, varied widely across donor age terciles and regression analysis was not performed to control for differences, comparisons between ischemic time strata from different donor age terciles should be made with caution.

Finally, although there was no measurable effect of ischemic time on hearts from donors aged 19 years or less within the given ranges of ischemic time, there is undoubtedly some duration of ischemic time in which survival is adversely affected. However, given the distribution of ischemic times observed in this study, this threshold could not be determined.

\section{Conclusions}

The findings in this study demonstrate that the effect of ischemic time on survival is dependent on donor age. These findings support the practice of procuring hearts from younger donors even when extended ischemic times are required. With adult-aged donors, a more conservative approach to ischemic time is justified, but in fact, when older organs are subjected to ischemic times up to 5.5 hours, they offer long-term survival comparable to those with shorter ischemic times. Nevertheless, clinically important differences in survival are observed when ischemic times extend beyond 5.5 to 6.25 hours, especially among recipients of hearts from advanced-age donors. Implicit in this observation is that stacking of risk factors (eg, subjecting grafts from advanced-age donors to extended ischemic times) predicts poor outcomes.

We thank UNOS for supplying these data and Katarina Anderson for her assistance with our analysis.



A

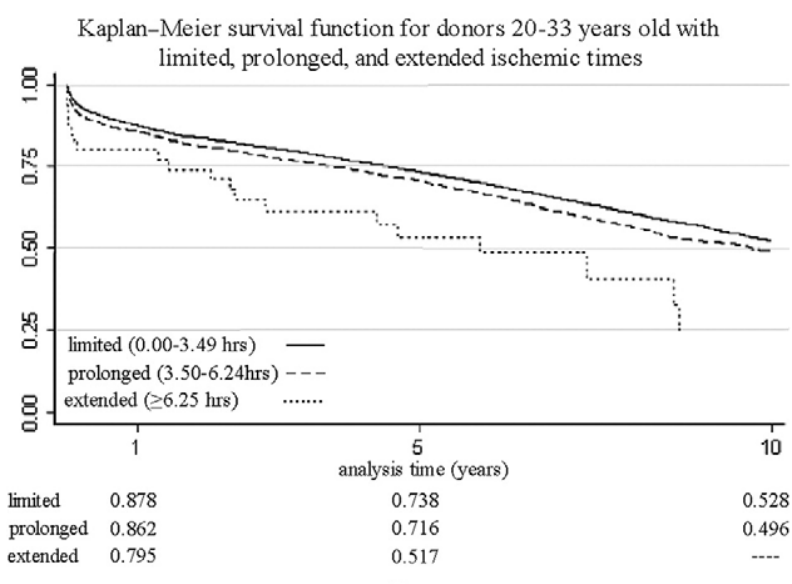

B

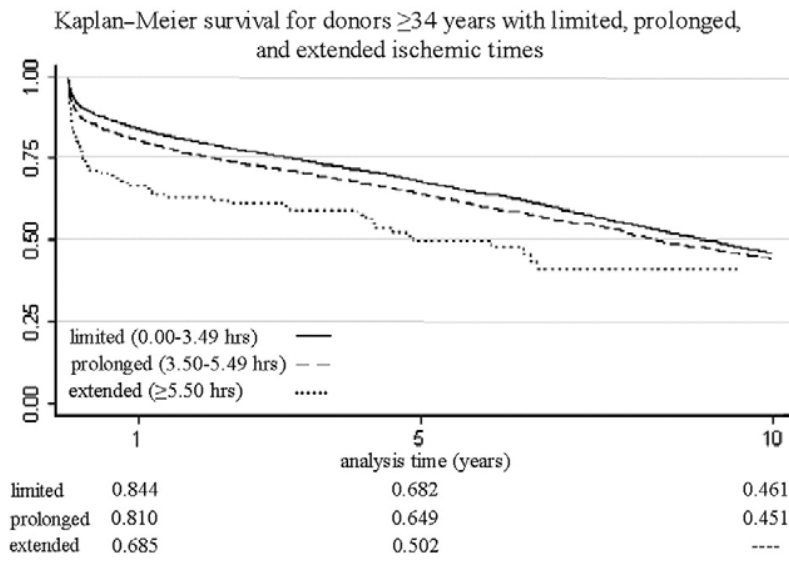

C

Figure 1. Kaplan-Meier survival analysis for 3 donor age ranges. $A$, Donors aged $\leq 19$ years. B, Donors aged 20 to 33 years with limited, prolonged, and extended ischemic times. C, Donors aged $\geq 34$ years with limited, prolonged, and extended ischemic times. 


\section{References}

1. Hanley JA, McNeil BJ. A method of comparing the areas under receiver operating characteristic curves derived from the same cases. Radiology. 1983;148:839-43.

2. Hanley JA, McNeil BJ. The meaning and use of the area under a receiver operating characteristic (ROC) curve. Radiology. 1982;143:29-36.

3. Pierce JC, Cornell RG. Integrating stratum-specific likelihood ratios with the analysis of ROC curves. Med Decis Making. 1993;13:141-51.

4. Chen JM, Levin HR, Michler RE, Prusmack CJ, Rose EA, Aaronson KD. Reevaluating the significance of pulmonary hypertension before cardiac transplantation: determination of optimal thresholds and quantification of the effect of reversibility on perioperative mortality. J Thorac Cardiovasc Surg. 1997;114:627-34.

5. Taylor DO, Edwards LB, Boucek MM, Trulock EP, Keck BM, Hertz MI. The Registry of the International Society for Heart and Lung
Transplantation: Twenty-First Official Adult Heart Transplant Report-2004. J Heart Lung Transplant. 2004;23:796-803.

6. Young JB, Naftel DC, Bourge RC, Kirklin JK, Clemson BS, Porter CB, et al. Matching the heart donor and heart transplant recipient. Clues for successful expansion of the donor pool: a multivariable, multiinstitutional report. The Cardiac Transplant Research Database Group. J Heart Lung Transplant. 1994;13:353-64.

7. Leman NR, Levi DS, Alejos JC, Wetzel GT. Predictors of graft longevity in pediatric heart transplantation. Pediatr Cardiol. 2005;26:762-7.

8. Mitropoulos FA, Odim J, Marelli D, Karandikar K, Gjertson D, Ardehali A, et al. Outcome of hearts with cold ischemic time greater than 300 minutes: a case matched study. Eur J Cardiothoracic Surg. 2005;28:143-8.

9. Morgan JA, John R, Weinberg AD, Kherani AR, Coletti NJ, Vigilance DW, et al. Prolonged donor ischemic time does not adversely affect long-term survival in adult patients undergoing cardiac transplantation. J Thorac Cardiovasc Surg. 2003;126:1624-33. 